\title{
Current outlook and future research needs for harvest weed seed control in North American cropping systems
}

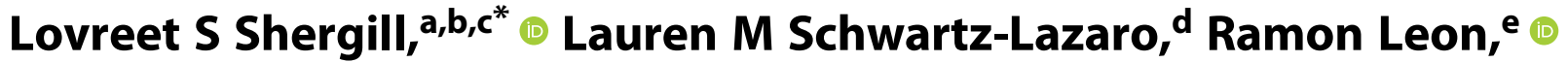 \\ Victoria J Ackroyd, ${ }^{\mathrm{f}}$ Michael L Flessner, ${ }^{\mathrm{g}}$ Muthukumar Bagavathiannan, ${ }^{\mathrm{h}} \odot$ \\ Wesley Everman, ${ }^{\mathrm{e}}$ Jason K Norsworthy, ${ }^{\mathrm{i}}$ Mark J VanGessel ${ }^{\mathrm{C}}$ and \\ Steven B Mirsky ${ }^{f}$
}

\begin{abstract}
Harvest weed seed control (HWSC) comprises a set of tools and tactics that prevents the addition of weed seed to the soil seed bank, attenuating weed infestations and providing a method to combat the development and spread of herbicide-resistant weed populations. Initial HWSC research efforts in North America are summarized and, combined with the vast area of crops suitable for HWSC, clearly indicate strong potential for this technology. However, potential limitations exist that are not present in Australian cropping systems where HWSC was developed. These include rotations with crops that are not currently amenable to HWSC (e.g. corn), high moisture content at harvest, untimely harvest, and others. Concerns about weeds becoming resistant to HWSC (i.e. adapting) exist, as do shifts in weed species composition, particularly with the diversity of weeds in North America. Currently the potential of HWSC vastly outweighs any drawbacks, necessitating further research. Such expanded efforts should foremost include chaff lining and impact mill commercial scale evaluation, as this will address potential limitations as well as economics. Growers must be integrated into large-scale, on-farm research and development activities aimed at alleviating the problems of using HWSC systems in North America and drive greater adoption subsequently.

(c) 2020 Society of Chemical Industry
\end{abstract}

Keywords: herbicide resistance management; integrated weed management; soil seed bank

\section{INTRODUCTION}

Herbicides have been the most effective tool for controlling weeds in agronomic crops due to their ease of application, high efficacy, low energy input, and low cost. Heavy reliance on herbicides has resulted in the widespread evolution of multiple herbicide-resistant weed populations throughout global cropping systems. Because of a lack of new herbicide mechanisms of action $^{1}$ and limited options to control current multiple herbicide-resistant weeds, integrated weed management (IWM) practices that rely on the use of multiple weed control strategies are urgently needed. ${ }^{2}$ Harvest weed seed control (HWSC) is a non-chemical weed control approach that has allowed Australian growers to effectively target weed seed populations at harvest. ${ }^{3}$ HWSC involves the collection and/or destruction of weed seeds during grain harvest, thus minimizing the contribution of seed rain to the soil seed bank. ${ }^{3}$ During crop harvest, the combine typically collects seeds retained by weeds above the harvest height and distributes them across the field with other crop residues. ${ }^{3,4}$ With HWSC, the weed seed-containing chaff material is concentrated in a heap (chaff carts) or narrow band (chaff lining and chaff tramlining), or is destroyed using impact mills [Integrated Harrington Seed Destructor ( $\mathrm{iHSD}^{\oplus}$ ), Seed Terminator, Redekop $^{\mathrm{T}}$, and WeedHOG], or either removed from the field with * Correspondence to: LS Shergill, Southern Agricultural Research Center, Mon-
tana State University, 748 Railroad Hwy, Huntley, MT 59037, USA. E-mail: lovreet.shergill@montana.edu

a Southern Agricultural Research Center, Montana State University, Huntley, MT b Beltsville Agricultural Research Center, USDA-ARS, Beltsville, MD

c Carvel Research and Education Center, University of Delaware, Georgetown, $D E$

d School of Plant, Environmental, and Soil Sciences, Louisiana State University AgCenter, Baton Rouge, LA

e Department of Crop and Soil Sciences, North Carolina State University, Raleigh, NC

f Sustainable Agricultural Systems Laboratory, Beltsville Agricultural Research Center, USDA-ARS, Beltsville, MD

g School of Plant and Environmental Sciences, Virginia Tech, Blacksburg, VA

h Department of Soil and Crop Sciences, Texas A\&M University, College Station, $T X$

i Department of Crop, Soil, and Environmental Sciences, University of Arkansas, Fayetteville, $A R$ 
straw residue (bale direct system) or concentrated with the straw in a windrow (narrow-windrow burning).

The primary success of any HWSC practice relies on the propensity of annual weed species to retain their seed until crop maturity at a height that enables collection during crop harvest. Once in the combine, these seeds can be effectively separated from the crop grain and subsequently managed. ${ }^{5}$ Fortunately, in North America, many annual weed species have high seed retention. ${ }^{5-7}$ In addition to seed retention, the success of HWSC may be limited by the weed life cycle, high moisture levels at harvest, extreme weather events, and/or weed adaptations due to HWSC selection. Here, we discuss opportunities and limitations for the use of HWSC in North American cropping systems and identify research needs for promoting HWSC in these systems.

\section{OPPORTUNITIES FOR HWSC USE IN NORTH AMERICA}

HWSC is not widely used in North American cropping systems. However, the increase in multiple herbicide-resistant weeds, lack of novel herbicide chemistries under development, and desire to minimize tillage (i.e., not rely on intensive tillage for weed control) have encouraged researchers and farmers to consider alternative non-chemical options such as HWSC. North American soybean cropping systems are a prime candidate for HWSC tactics due to the threat posed by herbicide-resistant weeds. ${ }^{5}$ In particular, HWSC may help manage Amaranthus palmeri (S.) Wats., which has high seed retention, numerous multiple herbicide-resistant populations, and few options for chemical control. ${ }^{5}$ Winter wheat production in the U.S. Northern Great Plains and Pacific Northwest is plagued by winter annual weed species; Bromus tectorum L., and Aegilops cylindrica Host. have high seed retention at crop maturity. ${ }^{8}$ Similarly, in Canada, problematic weeds of cereal, oilseed, and pulse crops, Setaria viridis (L.) P. Beauv., Chenopodium album L., and Bassia scoparia (L.) A. J. Scott, retain a high proportion of seed at crop maturity and thus are good candidates for HWSC control. ${ }^{9}$ Other weeds with high seed retention and thus greater HWSC potential include Sinapis arvensis L. and Galium spp. in dryland pulse crops, ${ }^{9-11}$ A. palmeri and Amaranthus tuberculatus (Moq.) J. D. Sauer in grain sorghum and corn, ${ }^{7}$ Sorghum halepense (L.) Pers. in grain sorghum, ${ }^{5}$ and Polygonum convolvulus L. and volunteer oilseed rape in multiple dryland systems. ${ }^{9,12}$

Current HWSC systems require harvest with a platform header, which represents over 75 million ha of crops $(\sim 36.5$ million ha soybean, $\sim 8.9$ million ha canola, $\sim 23.8$ million ha wheat, $\sim 3.9$ million ha barley, $\sim 1$ million ha rice, and $\sim 2.4$ million ha sorghum) in the USA and Canada. ${ }^{13,14}$ HWSC is most successful in crops that are harvested when the grain and crop residues are dry $(<16 \%)^{15}$ and where weed seeds are taken up into the combine. Crops swathed then subsequently harvested tend to improve seed retention for most weed species and HWSC efficacy as more weed seeds enter the combine harvester. ${ }^{9,10,12}$ The higher moisture levels found in some crops (and accompanying weeds) harvested before full maturity cause issues such as the clogging of combines and some HWSC systems. Furthermore, HWSC is not effective in crops in which weed seeds are not collected during harvest, such as cotton. There would need to be a change in picker design to enable weed seed collection for HWSC to be successful.

\section{NORTH AMERICAN RESEARCH EFFORTS THUS FAR}

\subsection{Weed seed retention studies}

The potential effectiveness of HWSC systems depends upon seed retention of the target weed species at crop maturity, enabling collection and processing at crop harvest. Amaranthus palmeri, A. tuberculatus, Ambrosia trifida L., C. album, Setaria faberi Herrm., Setaria pumila (Poir.) Roem. \& Schult., Digitaria sanguinalis (L.) Scop. and Ipomoea spp. are the most common and problematic weeds of corn, soybean, and cotton production systems in the USA. ${ }^{16,17}$ At maturity and concurrent with the crop harvest window, a high proportion ( $>80 \%$ ) of seeds are retained in Amaranthus spp., C. album, Setaria spp. and A. trifida.,18,19 Ipomoea hederacea Jacq. retained $75 \%$ and $85 \%$ of its seeds, whereas S. faberi retained $65 \%$ and $55 \%$ of its seeds in corn and soybean fields, respectively, in Illinois. ${ }^{6}$ In Minnesota, $80 \%$ seed retention was recorded for $A$. trifida at the time when $75 \%$ of soybeans were already harvested in the region. ${ }^{18}$ Similarly, high seed retention of $>96 \%$ was found in S. halepense in Texas. ${ }^{5}$ High seed retention of $>95 \%$ at soybean maturity in A. palmeri and A. tuberculatus was observed in a survey conducted across Arkansas, Tennessee, Illinois, Missouri, and Nebraska. ${ }^{19}$ In eastern Colorado, a high proportion (> 75\%) of seed was retained by $A$. cylindrica and B. tectorum at wheat maturity. ${ }^{8}$ In 2013 , a field survey of winter wheat fields near Pullman, WA found that $58 \%$ of seeds of Lolium perenne $\mathrm{L}$. ssp. multiflorum (Lam.) Husnot were retained above harvest height. $^{5}$

Bassia scoparia retains, on average, $99.8 \%$ of seeds at wheat harvest. ${ }^{9,12}$ However, B. scoparia plants harvested at $15 \mathrm{~cm}$ height could retain as many as 5400 seeds $\mathrm{m}^{-2} .{ }^{16}$ Therefore, harvest height would need to be lower than the current cutting height of $15-20 \mathrm{~cm}$ to maximize collection of B. scoparia seeds. Studies examining weed seed retention at crop harvest in Canada have also reported a high proportion (> 70\%) of seed retention in S. viridis, Galium spp., and Sinapis arvensis L. ${ }^{9-11}$ However, in Minnesota, lower seed retention (20\%) for S. viridis was observed in corn fields at harvest, ${ }^{20}$ reducing the effectiveness of HWSC tactics. The difference is due to the time of harvest in the different systems, suggesting that crop rotation and time of harvest are key for the retention numbers reported and should be considered by producers in different regions when determining the applicability of HWSC. Lower seed retention $(<50 \%)$ has also been reported in many other annual weed species such as Echinochloa crus-galli L. Beauv., Avena fatua L., Sonchus asper (L.) Hill, and S. arvensis L. in North America., $7,11,20,21$

\subsection{Impact on long-term weed population dynamics}

It is critical to know by how much and for how long soil seed bank additions must be reduced to realize a benefit to the farmer. HWSC is a harvest time management tool in that it affects only seeds entering, and not those exiting the soil seed bank. Because the soil seed bank buffers the weed community response to management, ${ }^{22}$ HWSC may take multiple seasons before gains are realized by the farmer. Such delays due to seed bank size and the proportion of seed controlled have been observed in other research. ${ }^{23}$ Linking the soil seed bank to the emerged weed community has proved elusive. ${ }^{24}$ Nonetheless, some North American HWSC studies have observed emerged weed population reductions after a single HWSC event. ${ }^{25,26}$ One modeling study has shown that $>80 \%$ of newly shed $A$. fatua seed must be eliminated to stop the population increasing, resulting in a stable 
population. ${ }^{27}$ Further research is needed in this area. HWSC must be used in an IWM approach and is not an effective stand-alone strategy. Overall HWSC efficacy depends upon length of weed seed dormancy, initial size of the seed bank, the amount of weed seed retention, the proportion of retained seed captured during the harvest operation, and the efficacy of the seed destruction mechanism utilized.

A simulation analysis was conducted using the Palmer amaranth management (PAM) model $^{28}$ for a hypothetical weed management scenario that featured a gradually increasing soil seed bank in a corn-soybean rotation over a 10-year period (Fig. 1). An in-depth description of the model is not provided here because the focus is rather to show what levels of HWSC efficacy are required for making long-term impacts on weed population sizes when HWSC is added to a standard weed management program. We illustrate this with $A$. palmeri control as a case study using the PAM model. It was assumed that the field had high A. palmeri population densities, representing levels expected following evolution of resistance to a previously used herbicide; the starting densities were three adult plants per $10 \mathrm{~m}^{2}$ area prior to crop harvest the previous fall and a seed bank density in the following spring of 65000 seed $\mathrm{m}^{-2}$. The herbicide program for corn (glyphosate-resistant) was 2,4-dichlorophenoxyacetic acid (2,4-D) burndown followed by (fb) $S$-metolachlor pre-emergence fb a premix of glyphosate $+S$-metolachlor + mesotrione (Halex ${ }^{\circledR}$ GT) tank-mixed with Atrazine post emergence. The program for soybean (dicamba-resistant) included dicamba burndown fb a premix of S-metolachlor + metribuzin (Boundary ${ }^{\circledR}$ ) pre-emergence $\mathrm{fb}$ dicamba $+\mathrm{S}$-metolachlor post emergence. The population in question was considered to exhibit high levels of resistance to glyphosate and acetolactate synthase (ALS) inhibitors, and low level resistance to protoporphyrinogen oxidase (PPO inhibitors). The biological parameters of the PAM model were obtained from the glyphosate-resistance simulation model for A. palmeri. ${ }^{29}$

The PAM model adequately accounts for intraspecific competitive response (i.e., density dependence) as well as interspecific

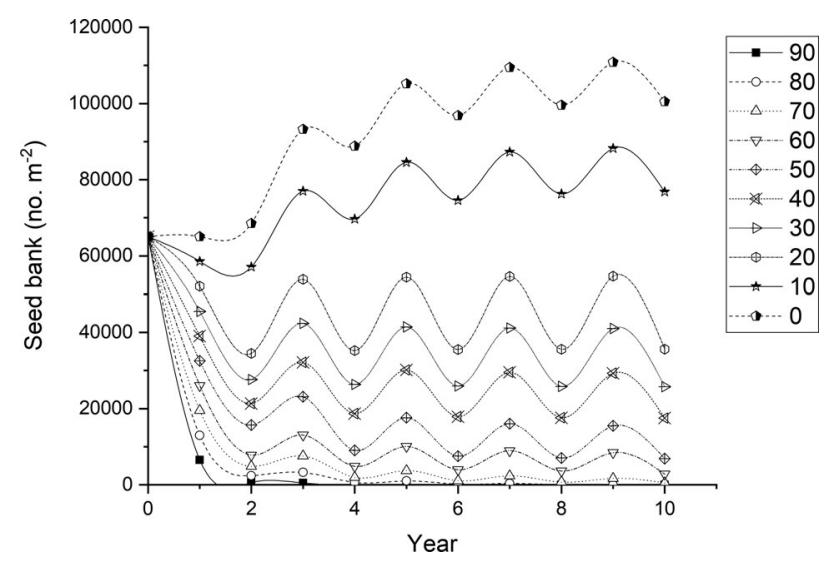

Figure 1 Simulation of the impact of a hypothetical harvest weed seed control tactic on the long-term soil seed bank size of Amaranthus palmeri under a less-robust weed management strategy that had a gradually increasing soil seed bank size in a corn-soybean rotation over a 10-year period. Annual fluctuations in soil seed bank size were influenced by varying weed management options utilized in the corn-soybean rotation (corn: 2,4-D burndown followed by (fb) S-metolachlor pre-emergence fb a premix of glyphosate $+S$-metolachlor + mesotrione (Halex GT) tankmixed with Atrazine post emergence; soybean: dicamba burndown fb a premix of $\mathrm{S}$-metolachlor + metribuzin (Boundary) pre-emergence $\mathrm{fb}$ dicamba + S-metolachlor post emergence). competition with the crop in simulating long-term weed population sizes. However, the PAM model does not account for environmental stochasticity nor does it consider spatial spread across production fields. More details of the PAM model parameterization and other considerations can be found in previous publications. ${ }^{29,30}$ During the simulations, efficacy levels for HWSC were allowed to differ from $10 \%$ to $90 \%$. Here, efficacy indicates percent reduction in viable seed after HWSC implementation out of the total seed produced by all uncontrolled weed escapes in a production field, which accounts for any seed that shattered prior to entering the combine, seeds that are not captured by the combine header due to cutting height and other reasons, and seeds that retain viability after being subjected to a given HWSC treatment.

Simulation results showed that HWSC efficacy as low as $20 \%$ applied annually was sufficient to reverse the trend and maintain the soil seed bank size at stable levels (Fig. 1), whereas $80 \%$ efficacy reduced the soil seed bank size to $<2 \%$ of the initial density level within 5 years. HWSC efficacy levels achieved in a season under practical field conditions may vary greatly due to the factors described above (e.g., shattering, seed production below harvest height, impact on seed viability, initial size of the seedbank and dormancy), yet levels $>50 \%$ have been common. ${ }^{5}$ Our model predicted that a $50 \%$ efficacy of HWSC implemented annually will lead to a $73 \%$ reduction in Palmer amaranth seed bank size in 5 years. Thus, annual inclusion of a HWSC tactic in an IWM program could potentially have a tremendous negative impact on long-term weed population size. However, it should be noted that the degree of influence may vary depending on the weed species in question, starting weed densities, background levels of herbicide resistance and the management program used, among others.

\subsection{HWSC methods explored in North America}

\subsubsection{Impact mills}

Impact mills are integrated into the combine as an aftermarket modification to destroy seeds mechanically during harvest. ${ }^{5,31}$ Several efforts to assess the efficacy of impact mills to target weeds of North American cropping systems have demonstrated their great potential for use as an HWSC tactic for IWM. ${ }^{15,28,32}$ In a recent study, an impact mill was highly effective in destroying seeds of ten weed species common to soybean fields in the Midwest and Mid-Atlantic regions of the USA, with $93.5-99.8 \%$ weed seed destruction in 2015 and $85.6-100 \%$ in $2017 .^{28}$ The difference between years was likely due to differences in the weed species tested and environmental conditions. Moreover, seed coats damaged by the Harrington Seed Destructor (HSD) impact mill increased seed mortality compared with control; seeds that appeared intact or potentially viable after passing through the impact mill were prone to rapid decay in the soil due to mechanical damage incurred during processing. In another study, the iHSD impact mill destroyed $>99 \%$ seeds in 11 of the 12 tested weed species of soybean and rice in the southern USA, whereas $3 \%$ seed survival was recorded for Xanthium strumarium L. ${ }^{9}$ It was noted that due to the high weed seed destruction (> 98\%) potential of the HSD impact mill, it could be highly effective in many cropping systems in western Canada and the U.S. Great Plains. ${ }^{32}$ In a recent study in Canada, initial testing of the Redekop $^{\mathrm{TM}}$ impact mill unit resulted in $>99 \%$ volunteer canola control and its efficacy was not affected by blade configuration and chaff feeding rate. $^{33}$ 


\subsubsection{Narrow-windrow burning}

Narrow-windrow burning involves the concentration of all harvest residues, including weed seeds, in narrow $(50-70 \mathrm{~cm})$ windrows using a chute mounted on the combine.,34 These windrows are later burned, destroying the weed seeds. ${ }^{34}$ Chutes used for narrow windrowing are relatively inexpensive and can be fabricated and assembled on-farm. Forming narrow windrows in soybean using a chute with a $41-\mathrm{cm}$ opening did not negatively impact harvest speed in a high-yielding environment $\left(4 \mathrm{t} \mathrm{ha}^{-1}\right)$ in Arkansas. ${ }^{35}$ Windrows should be burned before rain events or before the residue becomes compacted, which can limit the effectiveness of burning. Narrow-windrow burning reduced the viability and emergence of $L$. perenne ssp. multiflorum and could be effectively used as an IWM control strategy in eastern Washington and northern Idaho. ${ }^{36}$ Seeds of $L$. perenne ssp. multiflorum and A. palmeri were also found to be effectively destroyed by burning wheat and soybean windrows in Virginia. ${ }^{37}$ In Arkansas, seeds of A. palmeri, E. crus-galli, S. halepense, and Ipomoea lacunosa L. were destroyed by narrow-windrow burning regardless of the amount of wheat biomass present. ${ }^{35}$ Reduction of $A$. palmeri density was observed with narrow-windrow burning compared with conventional soybean harvest, when narrow-windrow burning was integrated with an effective herbicide program. ${ }^{25}$ The evidence suggests that North American growers could easily integrate narrow-windrow burning into current crop production to diversify weed management practices and reduce soil seed bank inputs. However, there are concerns related to windrow burning such as fire risks and smoke-related air quality issues. These concerns are discussed in detail in Section 4.2.4.

\subsubsection{Chaff carts}

Chaff carts are a HWSC method in which the weed seed containing chaff material is collected and removed from the field. ${ }^{5}$ Chaff carts are pulled behind the combine to collect the chaff as it leaves the combine. As used in Australia, during harvest chaff carts are strategically emptied at designated points to create rows of chaff piles. In autumn, a fire break is cultivated around these rows of chaff piles followed by burning to destroy the weed seeds. More frequently this chaff material is used as a valuable source of livestock feed where chaff is either grazed in situ or baled and removed for use in feedlots. Chaff collection and removal may slow weed invasions and reduce the expansion of weed patches. ${ }^{38}$ Several studies have been conducted in North American cropping systems to assess the impact of weed seed removal on weed populations and determine the suitability of chaff collection as a weed management strategy. Soybean harvest residue collection and removal was the most effective treatment to control $A$. palmeri, resulting in $67 \%, 70 \%$, and $41 \%$ reductions in weed density in the first, second, and third year of the study, respectively. ${ }^{25}$ Chaff collection was effective in reducing $A$. fatua seed dispersal, with $<10$ seeds $\mathrm{m}^{-2}$ collected $45 \mathrm{~m}$ beyond the A. fatua patch, compared with $>10$ seeds $\mathrm{m}^{-2}$ up to $145 \mathrm{~m}$ beyond the parent plants without chaff collection. ${ }^{38}$ In HWSC studies conducted across Virginia, up to $70 \%$ reductions in population densities of $L$. perenne ssp. multiflorum and $\sim 24 \%$ reduction in Ambrosia artemisiifolia L. were observed in the following crop compared with conventional harvest. ${ }^{26}$ However, effective management with herbicides under low weed seed pressure conditions rendered differences between HWSC and conventional harvest undetectable. Integrated use of propoxycarbazone and chaff collection during winter wheat harvest has been shown to reduce Lolium perenne L. ssp. multiflorum (Lam.) Husnot populations by $40 \%$ in western Oregon. ${ }^{39}$ Chaff collection or propoxycarbazone-only treatments were not effective. ${ }^{39}$

\section{CRITIQUE OF HWSC}

\subsection{Weed types/life cycles not effective for HWSC}

The life cycle of a weed can influence the effectiveness of HWSC. Vegetative propagation is not subject to HWSC. Perennial species easily persist in the presence of HWSC, but the seed of these species could be subjected to HWSC. For example, S. halepense, a perennial grass weed, had high seed retention of $>96 \%$ in Texas, ${ }^{5}$ whereas annual grass weeds such as S. viridis, E. crus-galli, A. fatua, S. asper, and S. pumila have low seed retention $(<40 \%)$ in North American regions. ${ }^{7,9,11,12,20,21}$ In general, summer annual grasses tend to shatter seeds prior to harvest and thus are not good targets for HWSC. Conversely, winter annual grasses appear to be better suited for management with HWSC. 8,26,36

Among broadleaf weeds, species such as Erigeron canadensis L. and Taraxacum officinale F. H. Wigg. that disperse seeds by wind prior to harvest are also not good targets for HWSC. Bassia scoparia has an indeterminate growth habit and plants are green at cereal harvest, making it unsuitable for HWSC without additional management strategies such as desiccation. Moreover, lowgrowing summer annual weeds including $D$. sanguinalis, Polygonum aviculare L., Amaranthus blitoides S. Wats., Euphorbia humistrata Engelm. and Portulaca oleracea L. are less likely to be impacted by HWSC due to their prostrate growth habit.

\subsection{HWSC challenges unique to North America}

\subsubsection{Crop rotation}

Currently, there are no effective techniques for implementing HWSC in corn and cotton. The design of the combine header for these crops means it does not capture all weed seeds present and, in fact, results in an increase in weed seed shatter more than seed collection by the combine. Rotations with crops that are not harvested with a platform header pose a serious challenge to the long-term effectiveness of HWSC by providing an opportunity for weeds to replenish the soil seed bank. However, including a crop in which HWSC cannot be used for 1 year is not uncommon in other regions of the world that rely on HWSC. This practice would reduce the selection pressure from HWSC placed on the weed species. However, the soil seed bank still needs to be controlled during the years when HWSC is not used so that any reductions in the soil seed bank are not undone at this time.

\subsubsection{Harvest timing, weather, and other concerns}

4.2.2.1. Timely harvest. Delayed harvest scenarios have become more common as weather patterns at crop harvest have become less predictable in recent years. For example, in 2019, precipitation at harvest resulted in harvest delays of up to 3 months in some regions. Wet weather patterns that delay harvest have the potential to allow more weed seeds to shatter and reduce HWSC efficacy. In addition, fields that are deemed an unharvestable loss (e.g., prevent planting, greater moisture in fields delay harvest) are often left unmanaged. Weeds left uncontrolled in these fields logically pose a threat to the effectiveness of HWSC practices. For example, $C$. album can increase its seed bank 14-fold in a single year, potentially setting back years of gains from HWSC. ${ }^{40}$

4.2.2.2. Geography and latitude. Northern latitudes increase the likelihood that summer crops are harvested after a killing frost and frost can increase the likelihood of weed seed shattering. 
Additional delays beyond frost further reduce weed seed capture during harvest. Harvest timing impacts capturing weed seeds with earlier harvest increasing the number of seeds captured (and therefore HWSC efficacy), as well as the moisture content of chaff, which is known to influence impact mill efficacy in certain cropping systems. Soybean chaff moisture content at $16 \%$ or higher resulted in clogging of cage mills. ${ }^{9}$ This observation has been supported by field work conducted in the Mid-Southern and Mid-Atlantic USA (Norsworthy and Mirsky, personal communication). Although it has been documented that wet material does not run smoothly through impact mills, it is not known how it would be processed by other HWSC technologies. Desiccants are commonly used in soybeans in the Mid-Southern and Southern USA as an aid to harvest. However, there is a need to research the impact of desiccants on the efficacy of HWSC (i.e., what is the effect of desiccant use on seed shatter?) and specific HWSC systems (i.e., is processing capacity improved by desiccant use?) and efficacy.

\subsubsection{Chaff lining and chaff tramlining}

Chaff lining and chaff tramlining do not destroy seeds or remove them from the field. Instead, these practices confine the weed seeds to narrow lines $(20-30 \mathrm{~cm})$ of residue directly behind the combine (chaff lining) or in the combine wheel tracks (tramlining). Tramlines are implemented with controlled traffic farming, in which all equipment in a field uses the same wheel paths. Because the crop is often sacrificed near these compacted areas, there is a lack of widespread use of controlled traffic systems in most regions of North America. The lack of controlled traffic systems will likely limit the adoption of chaff tramlining systems in North America. Both chaff lines and tramlines may be targeted with additional weed control tactics such as herbicides. Although ongoing research is evaluating chaff lining in North America, results are not yet available.

\subsubsection{Narrow-windrow burning}

Although the general concept of burning residue is not new to U.S. and Canadian growers, there are problems associated with it, such as fire risk, smoke-related air quality issues particularly near residential areas and for high-moisture crop residues, local restrictions on burning, and nutrient removal. The U.S. Environmental Protection Agency, Environment Canada, and state/provincial laws regulate the open burning of materials that may produce harmful air emissions or lead to wildfires, affecting human and environmental health. In addition, local government may have local ordinances that regulate open burning. Farmers can typically burn crop debris but burning plant material at certain times and in certain places may violate open burning laws and lead to criminal charges, fines, and civil liabilities. Therefore, it is important to know when it is permissible to burn field residues, and precautions should be taken to minimize risk and liability. Australian growers have stated that narrow-windrow burning is not sustainable because residue and nutrient removal is undesirable. Furthermore, waiting for the appropriate environmental conditions or having inadequate time to burn is problematic in certain North American regions due to excessive rain, early snowfall, shorter seasons or the need to plant a subsequent crop. For example, burning needs to occur immediately after harvest of crops such as soybeans which occurs in fall. This is more challenging than burning after harvesting cereal crops such as wheat which occurs in summer.

\subsubsection{Impact mills}

Impact mills have shown great success in weed seed destruction; however, the high initial cost associated with purchasing one or two mills (depending on the type and class of combine or mill) is not feasible for many growers. Additionally, there are annual operation and maintenance costs. Maintenance on mill blades, rotors, and additional parts is necessary to support mill functioning. However, the costs of impact mill use have been declining. Plant moisture content influences mill efficacy and can make use of a mill less attractive. In soybean, chaff moisture levels $>16 \%$ were found to clog the iHSD impact mill. ${ }^{15}$ The moisture content of both crops and weeds in North America is significantly greater than in Australia where the mills were developed and tested. Clogging can cause damage to the mills and delay harvest.

\subsubsection{Bale direct system}

The weed control efficacy of the bale direct system has not been examined in North America. This tactic bales straw and chaff fractions directly behind the combine to be sold as animal feed. Bale direct has limited adoption in Australia. ${ }^{41}$ The primary issue is a market for this material, which is region-specific in both Australia and North America, and the potential to spread weed seeds via the bale itself. Many weed seeds are not killed when digested by animals, and may be replanted in manure. ${ }^{42}$ Some areas bale crop residues in a two-pass system, in which the combine's spreader is disabled, depositing a windrow followed by a tractor-pulled baler. Anecdotal evidence and observations suggest significant amounts of weed seeds are not picked up by the baler and thus not removed from the field. Nutrient removal is also a concern with this system, as is the complicated and bulky equipment required (R. Newman, personal communication).

\subsubsection{Chaff carts}

Chaff carts are an effective option for seed and chaff removal. Chaff carts are pulled by the combine and thus add length to harvest set-ups, additional horsepower is also required. Growers may be hesitant to pull equipment with combines, ${ }^{41}$ particularly in regions with small fields, due to the difficulties in operating the machinery as greater length affects the turning radius. In addition, chaff dumps may need to be dealt with after harvest, which is an extra step and cost. Nutrient removal is also a concern, although less so than other HWSC practices because only the chaff fraction of crop residues is removed.

\subsection{Equipment needs to be updated for more efficient HWSC}

In addition to management practices, equipment plays a significant role in the success of HWSC. All current HWSC equipment modifies the combine in some way. Rather than retro-fitting combines, re-engineering the combine with HWSC in mind has the potential to overcome issues of high moisture, capacity, and horsepower requirements. Owing to issues with soybean residue clogging of current mills, higher moisture capacity impact mills are required for successfully targeting weed seeds in crops in North American cropping systems. Moreover, the ability to choose between chaff lining (under higher moisture conditions) and impact mill (under dry conditions or low crop biomass) with simple modifications could be critical for adoption. Combine size and horsepower is critical to the success of integrated HWSC impact mills. There are tradeoffs in available power to the mill and speed of harvest. ${ }^{43}$ Australian farmers noted increased horsepower requirement and fuel consumption with the addition of 
integrated impact mills. ${ }^{43}$ This extra horsepower draw will increase harvest times, which may limit adoption in many areas where precipitation is common at harvest. Any appreciable delays in soybean and wheat harvest have the potential to reduce grain quality, increase harvest losses, and impact the bottom line of the grower. To accommodate the added horsepower consumption of the impact mill, farmers would need to increase the horsepower of their harvest equipment. Combine size and horsepower restrictions can apply to impact mills and bale direct systems. However, newly developed impact mill systems that have a low power requirement such as WeedHOG, ${ }^{44}$ mean that most harvesters are capable of sufficient power to run these systems.

Currently, it is challenging to use HWSC in corn and cotton due to different designs of headers used in both crops. The cotton picker has a spindle-type header and the plants are herded towards a set of spindle bars as it moves down the cotton row. These spindles are designed to pick open cotton bolls only without damaging foliage or unopened bolls. Similarly, the corn header has long fingers with rollers at the base that reach in between the corn rows. The rollers cut and pull down the stalk, then chains break the ear of corn off the stalk, and augers rotate and feed the corn into the combine. The picking and cutting actions of these headers result in shattering weed seeds in the field. To successfully use HWSC in cotton and corn, the design of cotton pickers and corn headers needs to be improved to capture more weed seeds and is therefore an engineering opportunity.

\section{POTENTIAL FOR WEEDS TO ADAPT TO HWSC}

Mortality events or forces that reduce the survival of a plant community in a given area exert selection pressure for species that can survive or that have the necessary genetic diversity to adapt and reproduce at a higher rate than the mortality rate. ${ }^{45}$ Owing to HWSC selection pressure, changes in weed community composition and evolutionary changes within species are likely to occur. ${ }^{46}$ These changes must be expected and anticipated to develop strategies to manage selection pressure or adaptations to it. ${ }^{47}$

\subsection{Species composition shifts}

Shifts in weed community composition have been documented previously when practices such as mowing have been implemented in systems with annual weeds that predominantly reproduce by seed. ${ }^{48}$ In general, implementing control practices that prevent or reduce seed production and return to the soil seed bank favors perennial species that can regrow after removal of part of the shoot and especially those that can propagate vegetatively (i.e., via stolons, rhizomes, and tubers). This weed shift is particularly evident in no-till and conservation tillage systems. ${ }^{49}$ On farms where tillage and cultivation are frequently used, perennial species are not as successful; however, annual species producing large seeds, which can germinate deeper in the soil profile, are able to survive and increase their populations. ${ }^{50}$ If present in the agroecosystem and under conservation tillage production, HWSC could potentially favor vegetatively propagated perennial species such as S. halepense, Cyperus spp., and Cynodon dactylon (L.) Pers., among others.

Species with wind-dispersed seeds ${ }^{38}$ may exhibit higher rates of survival under HWSC than species with seeds dispersed by gravity. Observationally, mature wind-dispersed seed can be spread when the inflorescence is disturbed by harvesting equipment, which consequently will reduce the number of seeds subjected to the HWSC process. Disturbance by the combine header may also shatter weed seeds with other dispersal mechanisms and needs to be further evaluated (Kevin Bradley, personal communication).

\subsection{Early seed shatter or non-shattering}

Evolutionary adaptations in shattering timing and intensity have been documented in many species, such as S. halepense, Oryza sativa f. spontanea, and Raphanus raphanistrum L. ${ }^{51}$ Because HWSC depends on weeds retaining seeds in the inflorescence until harvest, individuals with mutations that allow more and earlier seed shattering are likely to contribute to the next generation. However, there are other mechanisms by which weed species can avoid harvesting. Recently, Australian cereal growers implementing HWSC have reported the appearance of biotypes of Lolium rigidum Gaudin with seemingly weaker culms that allow the inflorescence to detach more easily or to fall within the canopy, avoiding the harvester (Peter Newman, personal communication). However, no evidence of adaptation in L. rigidum was observed following use of HWSC for 5 to 10 years. ${ }^{52}$ Such non-shattering adaptations do not have an obvious fitness penalty. Species such as semi-wild wheat in China, and Eleusine coracana in Africa, have evolved an easily broken rachis and disarticulating spikelets facilitating seed shattering. ${ }^{53,54}$

Earlier or delayed flowering might help weeds avoid seed removal by HWSC. In California, R. raphanistrum exhibited earlier bolting and flowering as an adaptation for survival in these cropping systems. ${ }^{55,56}$ Indeed, recurrent selection resulted in a $50 \%$ reduction in time to flowering in Australian $R$. raphanistrum. ${ }^{46}$ Generally, as the time from emergence to flowering decreases, fecundity also decreases, representing a potential fitness penalty for this adaptation. ${ }^{57}$ In more dramatic cases, the life cycle of the weed can change. This was the case with Beta vulgaris subsp. maritima (L.) Arcang., which shifted from an annual to a biennial habit by introgressing genes from cultivated sugar beet (Beta vulgaris L.). ${ }^{58}$

Populations of a weed species that are not displaced by HWSC can also adapt to increase their reproduction rate above the mortality rate caused by the overall weed control program. Although adaptations that can mitigate HWSC are possibly more complex than the single point mutations responsible for target-site herbicide resistance, if selection pressure is high enough and the populations of the weed species possess enough genetic diversity, it is feasible that the evolution of mechanisms of resistance, tolerance, or avoidance of HWSC could occur. ${ }^{24,59}$ Rhizome development and growth habit (upright versus prostrate) are genetically very similar among some grasses, further indicating the potential for adaptation to HWSC. ${ }^{60}$ Examples of adaptation in response to non-chemical weed control include crop mimicry, changes in plant architecture, earlier reproductive maturity, enhanced seed dormancy, and earlier seed shattering patterns. ${ }^{38}$ Perhaps the best-known example is how Echinochloa crus-galli var. oryzicola evolved a morphology mimicking the rice plant at vegetative stages, flowers at the same time as the crop, and has an inflorescence that mimics the rice flower. ${ }^{61,62}$ It is believed that handweeding in east Asia selected for biotypes that resembled the crop, making it more difficult for farmers to detect and remove all the individuals of this weed species. ${ }^{63,64}$ Another example is the contamination of lentil seed with Vicia sativa L. seeds. In this case, the latter evolved seeds that had the same flattened shape and size as the former, which makes it difficult to clean the seed 
easily. ${ }^{61}$ This adaption was due to a single recessive mutation with Mendelian inheritance. ${ }^{65}$

\subsection{Post-harvest seed production}

Post-harvest weed control to prevent seed production is a common practice that many southern U.S. and northern Great Plains growers have implemented. ${ }^{66,67}$ Post-harvest seed production can occur from new flushes of germination or the regrowth of larger weeds or perennial weeds. This can potentially decrease the effectiveness of HWSC systems that do not immediately destroy weed seeds collected during harvest, such as chaff lining, chaff tramlining, and chaff carts (unless burned). Seeds that are not destroyed could begin to germinate or even grow and set seed prior to a killing frost, which does not always occur in some parts of the USA. Such scenarios lead to even more additions to the soil seed bank. Research has shown that some weeds can produce a seed head and viable seed when only a few inches tall and from new growth when decapitated. ${ }^{67}$

\subsection{Implications of weed adaptations}

Acknowledgment that weeds will adapt to all forms of weed control including HWSC should prompt the design of IWM strategies not only intended to maximize weed control, but also to avoid or at least delay the evolution of adaptive traits such as those discussed above. It is worth noting that adaptations in response to HWSC have not been observed to date, indicating that such changes will take time and allow for prevention opportunities. As has been proposed for herbicide resistance management, use of complementary and diverse weed control actions is needed to reduce the chance of selecting resistant individuals. If shifts in flowering or seed shattering occur, varying HWSC timing must become a key component of this technology. This can be done by rotating crops or varieties with different times to maturity or varying planting dates. In the case that adaptation takes the form of shorter plant height, the use of crops with denser and/or taller canopies will be countered by reducing the ability of the weed to access sunlight. For example, due to shade intolerance in $L$. rigidum, increased crop competition resulted in higher proportions of its seed in the upper crop canopy $(>40 \mathrm{~cm}) .^{52}$

It is important to mention that the potential fitness penalties associated with adaptations to HWSC might not be sufficiently serious for the original 'susceptible' biotype to become predominant if HWSC is removed from the management plan. The reason being that any adaptation that allows a weed species to maintain a reproductive rate that is higher than the mortality caused by HWSC will likely have to also involve complementary or compensatory mechanisms. For example, in many cases, increased seed shattering co-evolves with changes in seed dormancy (i.e., deeper or more variable dormancy). ${ }^{68,69}$ Evolution of earlier flowering can be accompanied by an increase in flower number and the duration of flowering. ${ }^{55}$ Therefore, the fact that the morphology of the plant changes, potentially making it less competitive, does not mean that it will not be able to evolve a demographic pattern that allows population growth with or without HWSC being part of the weed management system.

The best way to slow adaptation is by exposing few individuals to the selection pressure, i.e., establishing and maintaining low weed density. When HWSC is successfully executed within a diverse weed management approach, the soil seed bank is depleted. This proactive, as opposed to reactive, approach is needed for truly sustainable weed management.

\section{RESEARCH NEEDS}

To date, research in North America has focused on weed seeds (i.e., shattering timing and kill by impact mills), with limited field studies of HWSC. Promising results of initial and on-going research, combined with the enormous amount of acreage harvested with platform headers strongly indicate the need for continued efforts. The most important next step for both research and adoption in North America is to evaluate HWSC in long-term experiments and commercial farms across the continent. For the reasons stated above, chaff lining and impact mills should be prioritized. This collaborative work between researchers, farmers, and industry will answer many open questions including economics, use in crop rotations, suitability for different regions and cropping systems, and integration with other weed management tactics. On-farm evaluation will also address the suitability of equipment for use with high moisture residues and provide data to support design refinements. Long-term use of HWSC and its impact on the soil seed bank and shifts in species composition can also be addressed this way.

Additional seed retention research is also needed. Many weeds of concern have been evaluated with promising results, so future research needs to focus on management and environmental factors potentially influencing seed shatter, such as weather events, planting and crop maturity timings, use of desiccants, seed loss at the header, and the like. Researchers must be vigilant for adaptations and shifts in weed species composition in response to HWSC. Investigating the potential for obvious adaptations, such as early seed shatter, should occur to inform proactive resistance mitigation strategies. Growers must be integrated into large-scale, on-farm research efforts when possible to drive greater adoption while identifying and correcting the limitations of HWSC.

\section{CONCLUSIONS}

Interest in HWSC has increased among researchers in North America within the past decade as growers continue to struggle to manage multiple herbicide-resistant weeds. The need for alternative weed control technologies is largely driven by the widespread occurrence of non-target site resistance mechanisms and the fact that there are limited new herbicide options and no new site of action herbicides under commercialization. With regard to HWSC research, much of the effort to date has focused on seed retention of the most common and troublesome weeds of production systems to understand the feasibility of capturing and/or destroying seeds of these species during harvest. Research to test HWSC tactics in commercial production fields is ongoing and the impact of these tactics on weed population dynamics over multiple growing seasons is being evaluated.

Although the benefits of HWSC strategies are obvious, limitations to adoption must be understood. Research has shown that narrow-windrow burning in soybean can be highly effective in killing the seeds of many, but not all weed species. ${ }^{35}$ However, adoption of such a practice may be limited by environmental regulations in some regions of North America. Other regional limitations may involve crop maturity and harvest relative to maturity or dry down of some weeds. For instance, in the Midwest, soybean is typically harvested after a killing frost, and it is likely that weed death prior to crop harvest aids the ability to successfully incorporate an impact mill into these production systems, although further research is needed. Conversely, in more southern regions of North America where soybean is harvested prior to a killing frost, weeds like $A$. palmeri with bulky, moist stems make use of an 
impact mill virtually impossible without some means of desiccation. Other HWSC limitations include the inability to capture weed seeds during the harvest operations of crops such as cotton, peanut, or corn.

Finally, HWSC has extensive potential in wheat and soybean production systems and possibly other similarly harvested crops. HWSC tactics found to be most impactful in one region may have differing degrees of success when evaluated under contrasting weed spectrums, environmental conditions, and production practices including planting dates, crop maturity, and irrigation practices, among others. There is still a wealth of research needed before HWSC is widely integrated into North American cropping systems, and growers must be actively engaged in this research if a high level of adoption is to be expected.

\section{REFERENCES}

1 Duke SO, Why have no new herbicide modes of action appeared in recent years? Pest Manag Sci 68:505-512 (2012).

2 Swanton CJ and Weise SF, Integrated weed management: the rationale and approach. Weed Technol 5:657-663 (1991).

3 Walsh M, Newman P and Powles S, Targeting weed seeds in-crop: a new weed control paradigm for global agriculture. Weed Technol 27:431-436 (2013).

4 Broster JC, Walsh MJ, and Chambers AJ, Harvest weed seed control: the influence of harvester set up and speed on efficacy in South-Eastern Australia wheat crops, Presented at the 20th Australasian Weeds Conference, 2016, Perth, Western Australia, 38-41.

5 Walsh MJ, Broster JC, Schwartz-Lazaro LM, Norsworthy JK, Davis AS, Tidemann BD et al., Opportunities and challenges for harvest weed seed control in global cropping systems. Pest Manag Sci 74: 2235-2245 (2018).

6 Davis AS, Weed seed pools concurrent with corn and soybean harvest in Illinois. Weed Sci 56:503-508 (2008).

7 Schwartz-Lazaro LM, Green JK and Norsworthy JK, Seed retention of Palmer amaranth (Amaranthus palmeri) and barnyardgrass (Echinochloa crus-galli) in soybean. Weed Technol 31:617-622 (2017).

8 Soni N, Nissen SJ, Westra P, Norsworthy JK, Walsh MJ and Gaines TA, Seed retention of winter annual grass weeds at winter wheat harvest maturity shows potential for harvest weed seed control. Weed Technol 34:266-271 (2020)

9 Beckie HJ, Blackshaw RE, Harker KN and Tidemann BD, Weed seed shatter in spring wheat in Alberta. Can J Plant Sci 98:107-114 (2017).

10 Burton NR, Beckie HJ, Willenborg CJ, Shirtliffe SJ, Schoenau JJ and Johnson EN, Evaluating seed shatter of economically important weed species. Weed Sci 64:673-682 (2016).

11 Tidemann BD, Hall LM, Harker KN, Beckie HJ, Johnson EN and Stevenson FC, Suitability of wild oat (Avena fatua), false cleavers (Galium spurium), and volunteer canola (Brassica napus) for harvest weed seed control in western Canada. Weed Sci 65:769-777 (2017).

12 Burton NR, Beckie HJ, Willenborg CJ, Shirtliffe SJ, Schoenau JJ and Johnson EN, Seed shatter of six economically important weed species in producer fields in Saskatchewan. Can J Plant Sci 97:266-276 (2017).

13 USDA-NASS, NASS - Quick Stats, USDA-Natl Agric Stat Serv, 2020. Available: https://data.nal.usda.gov/dataset/nass-quick-stats [22 May 2020].

14 Statistics Canada, Principal field crop areas, March 2020. Available: https://www150.statcan.gc.ca/n1/daily-quotidien/200507/ dq200507a-eng.htm [22 May 2020].

15 Schwartz-Lazaro LM, Norsworthy JK, Walsh MJ and Bagavathiannan MV, Efficacy of the integrated Harrington seed destructor on weeds of soybean and rice production systems in the southern United States. Crop Sci 57:2812-2818 (2017).

16 Van Wychen L, Baseline survey of the most common and troublesome weeds in the United States and Canada. National Survey Data set. Weed Sci Soc Am (2015). Available: http://wssa.net/wp-content/ uploads/2015-Weed-Survey_Baseline.xIsx [26 February 2020].

17 Van Wychen L, Survey of the most common and troublesome weeds in broadleaf crops, fruits \& vegetables in the United States and Canada. National Survey Data set. Weed Sci Soc Am (2016). Available: http://
wssa.net/wp-content/uploads/2016_Weed_Survey_Final._ xlsx. [21 February 2020].

18 Goplen JJ, Sheaffer CC, Becker RL, Coulter JA, Breitenbach FR Behnken LM et al., Giant ragweed (Ambrosia trifida) seed production and retention in soybean and field margins. Weed Technol $\mathbf{3 0}$ : 246-253 (2016).

19 Schwartz-Lazaro LM, Norsworthy JK, Young BG, Bradley KW, Kruger GR, Davis VM et al., Tall waterhemp (Amaranthus tuberculatus) and Palmer amaranth (Amaranthus palmeri) seed production and retention at soybean maturity. Weed Technol 30:284-290 (2016).

20 Forcella F, Peterson DH and Barbour JC, Timing and measurement of weed seed shed in corn (Zea mays). Weed Technol 10:535-543 (1996).

21 Shirtliffe SJ, Entz MH and Van Acker RC, Avena fatua development and seed shatter as related to thermal time. Weed Sci 48:555-560 (2000).

22 Harper $J$ and Gajic D, Experimental studies of the mortality and plasticity of a weed. Weed Res 1:91-104 (1961).

23 Burnside OC, Wilson RG, Wicks GA, Roeth FW and Moomaw RS, Weed seed decline and buildup in soils under various corn management systems across Nebraska. Agron J 78:451-454 (1986).

24 Haring SC and Flessner ML, Improving soil seed bank management. Pest Manag Sci 74:2412-2418 (2018).

25 Norsworthy JK, Korres NE, Walsh MJ and Powles SB, Integrating herbicide programs with harvest weed seed control and other fall management practices for the control of glyphosate-resistant Palmer amaranth (Amaranthus palmeri). Weed Sci 64:540-550 (2016).

26 Beam SC, Mirsky S, Cahoon C, Haak D and Flessner M, Harvest weed seed control of Italian ryegrass [Lolium perenne L. ssp. multiflorum (Lam.) Husnot], common ragweed (Ambrosia artemisiifolia L.), and Palmer amaranth (Amaranthus palmeri S Watson). Weed Technol. 33:627-632 (2019)

27 Tidemann BD, Hall LM, Harker KN and Alexander BCS, Identifying critical control points in the wild oat (Avena fatua) life cycle and the potential effects of harvest weed-seed control. Weed Sci 64: 463-473 (2016)

28 Shergill LS, Bejleri K, Davis A and Mirsky SB, Fate of weed seeds after impact mill processing in midwestern and mid-Atlantic United States. Weed Sci 68:92-97 (2020).

29 Neve P, Norsworthy JK, Smith KL and Zelaya IA, Modelling evolution and management of glyphosate resistance in Amaranthus palmeri. Weed Res 51:99-112 (2011).

30 Lindsay K, Popp M, Norsworthy J, Bagavathiannan M, Powles S and Lacoste M, PAM: decision support for long-term Palmer amaranth (Amaranthus palmeri) control. Weed Technol 31:915-927 (2017).

31 Guzzomi AL, Ryan M, Saunders C and Walsh MJ, Reducing the integrated Harrington seed destructor power requirements through chaff fraction optimization. Appl Eng Agric 33:695-701 (2017).

32 Tidemann BD, Hall LM, Harker KN and Beckie HJ, Factors affecting weed seed devitalization with the Harrington seed destructor. Weed Sci 65:650-658 (2017).

33 Tidemann B, Kubota $\mathrm{H}$, Reid $\mathrm{P}$ and Zuidhof J, Initial testing of a cage mill with an incorporated blade system on volunteer canola. Can $J$ Plant Sci (2020). https://doi.org/10.1139/CJPS-2020-0010.

34 Walsh $M$ and Newman $P$, Burning narrow windrows for weed seed destruction. Field Crops Res 104:24-30 (2007).

35 Green JK, Norsworthy JK and Scott RC, Narrow-windrow burning of soybean chaff in an effort to decrease the return of weed seed to the soil seedbank. Soybean Res Stud 23:126-128 (2016).

36 Lyon DJ, Huggins DR and Spring JF, Windrow burning eliminates Italian ryegrass (Lolium perenne ssp multiflorum) seed viability. Weed Technol 30:279-283 (2016).

37 Flessner ML, Beam SC, Pittman KB and Everman WJ, Harvest Weed Seed Control, VA Coop Ext Pub No SPES-135NP (2019). Available: https://www.pubs.ext.vt.edu/content/dam/pubs_ext_vt_edu/spes/ spes-135/SPES-135NP.pdf. [accessed 20 April 2020].

38 Shirtliffe SJ and Entz $\mathrm{MH}$, Chaff collection reduces seed dispersal of wild oat (Avena fatua) by a combine harvester. Weed Sci 53: 465-470 (2005).

39 Roerig KC, Hulting AG, Curtis DW and Mallory-Smith C, Sustaining herbicide efficacy: preventing the distribution of multiple resistant Italian ryegrass seed during winter wheat harvest by removal/destruction of chaff, in 2015 Western Society of Weed Science Annual Meeting, ed. by McCloskey B. Western Society of Weed Science, Portland, OR, p. 76 (2015).

40 Leguizaamón ES and Roberts HA, Seed production by an arable weed community. Weed Res 22:35-39 (1982). 
41 Walsh M, Ouzman J, Newman P, Powles S and Llewellyn R, High levels of adoption indicate that harvest weed seed control is now an established weed control practice in Australian cropping. Weed Technol 31:341-347 (2017).

42 Blackshaw RE and Rode LM, Effect of ensiling and rumen digestion by cattle on weed seed viability. Weed Sci 39:104-108 (1991).

43 Anonymous, Residue Management at Harvest: Weed Seed Options. Leederville, Western Australia: Aspermont Ltd., 2018. Available: https://weedsmart.org.au/wp-content/uploads/2018/06/RR_1802_ weedsmart.pdf. [accessed 20 April 2020].

44 Anonymous, Tecfarm is pleased to announce the release to market of the WeedHOG. The revolutionary seed mill with a difference!. Bruce Rock, WA: Tecfarm; 2020. Available: http://www.tecfarm. com.au/tfwp/?p=1200 [20 June 2020].

45 Storkey J, Moss SR and Cussans JW, Using assembly theory to explain changes in a weed flora in response to agricultural intensification. Weed Sci 58:39-46 (2010).

46 Ashworth MB, Walsh MJ, Flower KC, Vila-Aiub MM and Powles SB, Directional selection for flowering time leads to adaptive evolution in Raphanus raphanistrum (wild radish). Evol Appl 9: 619-629 (2016).

47 Jordan NR and Jannink J, Assessing the practical importance of weed evolution: a research agenda. Weed Res 37:237-246 (1997).

48 Steenwerth KL, Calderón-Orellana A, Hanifin RC, Storm C and McElrone AJ, Effects of various vineyard floor management techniques on weed community shifts and grapevine water relations. Am J Enol Vitic 67:153-162 (2016).

49 Légère $A$ and Samson $N$, Tillage and weed management effects on weeds in barley-red clover cropping systems. Weed Sci $\mathbf{5 2}$ 881-885 (2004)

50 Buhler DD, Influence of tillage systems on weed population dynamics and management in corn and soybean in the Central USA. Crop Sci 35:1247-1258 (1995).

51 Ellstrand NC, Heredia SM, Leak-Garcia JA, Heraty JM, Burger JC, Yao L et al., Crops gone wild: evolution of weeds and invasives from domesticated ancestors. Evol Appl 3:494-504 (2010).

52 Walsh MJ, Broster JC, Aves C and Powles SB, Influence of crop competition and harvest weed seed control on rigid ryegrass (Lolium rigidum) seed retention height in wheat crop canopies. Weed Sci 66: 627-633 (2018).

53 De Wet JM and Harlan JR, Weeds and domesticates: evolution in the man-made habitat. Econ Bot 29:99-108 (1975).
54 Sun Q, Ni Z, Liu Z, Gao J and Huang T, Genetic relationships and diversity among tibetan wheat, common wheat and European spelt wheat revealed by RAPD markers. Euphytica 99:205-211 (1998).

55 Hegde SG, Nason JD, Clegg JM and Ellstrand NC, The evolution of California's wild radish has resulted in the extinction of its progenitors. Evolution 60:1187-1197 (2006).

56 Ridley CE, Kim S and Ellstrand NC, Bidirectional history of hybridization in California wild radish, Raphanus sativus (Brassicaceae), as revealed by chloroplast DNA. Am J Bot 95:1437-1442 (2008).

57 Taghizadeh MS, Nicolas ME and Cousens RD, Effects of relative emergence time and water deficit on the timing of fruit dispersal in Raphanus raphanistrum L. Crop Pasture Sci 63:1018-1025 (2012).

58 Mücherl T, Hessel P, Pohl-Orf ZM, Ellstrand NC and Bartschl D, Characterization of weed beet in Germany and Italy. J Sugar Beet Res 37:1938 (2000).

59 Neve $\mathrm{P}$, Vila-Aiub $\mathrm{M}$ and Roux F, Evolutionary-thinking in agricultural weed management. New Phytol 184:783-793 (2009).

60 Yun L, Larson SR, Mott IW, Jensen KB and Staub JE, Genetic control of rhizomes and genomic localization of a major-effect growth habit QTL in perennial wildrye. Mol Genet Genomics 289:383-397 (2014).

61 McElroy JS, Vavilovian mimicry: Nikolai Vavilov and his little-known impact on weed science. Weed Sci 62:207-216 (2014).

62 Barrett SH, Crop mimicry in weeds. Econ Bot 37:255-282 (1983).

63 Barrett SC and Seaman DE, The weed flora of Californian rice fields. Aquat Bot 9:351-376 (1980).

64 Barrett SC and Wilson BF, Colonizing ability in the Echinochloa crus-galli complex (barnyard grass). I. Variation in life history. Can J Bot 59: 1844-1860 (1981).

65 Rowlands D, A case of mimicry in plants-Vicia sativa L. in lentil crops. Genetica 30:435-446 (1959).

66 Crow WD, Steckel LE, Hayes RM and Mueller TC, Evaluation of POSTharvest herbicide applications for seed prevention of glyphosateresistant Palmer amaranth (Amaranthus palmeri). Weed Technol 29: 405-411 (2015).

67 Low RH, Prevention and Control Options for Glyphosate-Resistant Kochia (Kochia scoparia). Masters Thesis, University of Alberta (2016).

68 Londo J and Schaal B, Origins and population genetics of weedy red rice in the USA. Mol Ecol 16:4523-4535 (2007).

69 Ishikawa R, Toki N, Imai K, Sato Y, Yamagishi H, Shimamoto Y et al., Origin of weedy rice grown in Bhutan and the force of genetic diversity. Genet Resour Crop Evol 52:395-403 (2005). 